\title{
Fabrication and Characterization of Near Infrared Molybdenum Disulfide/Silicon Heterojunction Photodetector by Drop Casting Method
}

\author{
Haroon Rashid 1,*, Norhana Arsad 1,*, Harith Ahmad 2,3, Ahmad Ashrif A. Bakar ${ }^{1}$ and Mamun Ibne Reaz 1,* \\ 1 Department of Electrical, Electronic and Systems Engineering, Faculty of Engineering and Built Environ- \\ ment, Universiti Kebangsaan Malaysia, 43600 UKM Bangi, Selangor, Malaysia; haroon@ukm.edu.my (H.R.); \\ noa@ukm.edu.my (N.A.); ashrif@ukm.edu.my (A.A.A.B); mamun@ukm.edu.my (M.I.R.) \\ 2 Photonics Research Centre, University of Malaya, 50603 Kuala Lumpur, Malaysia \\ 3 Department of Physics, Faculty of Science, University of Malaya, 50603 Kuala Lumpur, Malaysia \\ * Correspondence: haroon@ukm.edu.my (H.R.); noa@ukm.edu.my (N.A.); mamun@ukm.edu.my (M.I.R.)
}

\begin{abstract}
In this work, a highly efficient, molybdenum disulfide $\left(\mathrm{MoS}_{2}\right)$ based near infrared (NIR) heterojunction photodetector is fabricated on a Si substrate using a cost-effective and simple drop casting method. A non-stoichiometric and inhomogeneous $\mathrm{MoS}_{2}$ layer with a S/Mo ratio of 2.02 is detected using energy dispersive $\mathrm{X}$-ray spectroscopy and field emission scanning electron microscope analysis. Raman shifts are noticed at $382.42 \mathrm{~cm}^{-1}$ and $407.97 \mathrm{~cm}^{-1}$, validating MoS2 thin film growth with a direct bandgap of $2.01 \mathrm{eV}$. The fabricated n-MoS $/ \mathrm{p}-\mathrm{Si}$ photodetector is illuminated with a $785 \mathrm{~nm}$ laser at different intensities, and demonstrate the ability of the photodetector to work in both regions, the forward biased and reverse biased from above $1.5 \mathrm{~V}$ and less than $-1.0 \mathrm{~V}$. The highest responsivity, $\mathrm{R}$ is calculated to be $0.52 \mathrm{~A} / \mathrm{W}$ while the detectivity $\mathrm{D}^{*}$ is $4.08 \times 10^{10}$ Jones for an incident light intensity of $9.57 \mathrm{~mW} / \mathrm{cm}^{2}$. The minimum rise and fall times are calculated as 1.77 $\mathrm{ms}$ and $1.31 \mathrm{~ms}$ for an incident laser power of $9.57 \mathrm{~mW} / \mathrm{cm}^{2}$ and $6.99 \mathrm{~mW} / \mathrm{cm}^{2}$ respectively at a direct current bias voltage of $10 \mathrm{~V}$. The demonstrated results are promising for the low-cost fabrication of a thin $\mathrm{MoS}_{2}$ film for photonics and optoelectronic device applications.
\end{abstract}

Keywords: $\mathrm{MoS}_{2}$; photodetector; Raman; drop casting; infrared; thin film

\section{Introduction}

Transition metal di chalcogenides (TMDC) have recently drawn a lot of interest owing to their exceptional optical and electronic properties, which give them value for optoelectronic applications. TMDC have a typical structure of $\mathrm{MX}_{2}$, where $\mathrm{M}$ being a transition metal, commonly Mo and $\mathrm{W}$ and $\mathrm{X}$ being a chalcogen such as $\mathrm{S}$ and Se. Amongst these TMDC, MoS 2 has the layered structure of S-Mo-S with one Mo atom covalently bonded to two $\mathrm{S}$ atoms. Furthermore, $\mathrm{MoS}_{2}$ has a particular advantage over graphene in that graphene has a zero bandgap, while monolayer $\mathrm{MoS}_{2}$ has an indirect bandgap of $1.29 \mathrm{eV}$ and direct transition starts from $1.8 \mathrm{eV}$. Also, it has stable crystalline structure, size dependent bandgap and found in either semiconductor or metallic nature. It is widely reported in various applications ranging from sensors, transistors, and solar cells to optical fiber lasers and photodetectors ${ }^{1-10}$.

$\mathrm{MoS}_{2}$ can be synthesized using a variety of techniques, depending on the properties that the application requires. In its bulk form, these 2D materials have weak Van der Waals forces between the layers, and as such mechanical exfoliation has been an easy and common method of obtaining 2D material films that are a few layers in thickness. In fact, the use of scotch tape has been reported extensively as a simple method of obtaining a $\mathrm{MoS}_{2}$ film that are only a few layers thick, but not appropriate for sizable production due to its inability to control the shape of the flakes obtained, nor their thickness and size ${ }^{11}$. In anticipation of a single atomic layer, or two to three layers thick $\mathrm{MoS}_{2}$ films, liquid 
exfoliation is instead used. Also, ultra-thin layers are obtained by the sonication of an exfoliated solvent. The drawback of this approach however is that the process can cause defects in the fabricated layers and reduce the number of layers obtained, thus limiting its applications ${ }^{12,13}$. Another widely used method to obtain thin $\mathrm{MoS}_{2}$ layers is chemical vapor deposition (CVD) where atomically thin layers can be synthesized by thermal evaporation or sulfurization on a precursor reagent such as $\mathrm{Mo}^{14}, \mathrm{MoO}_{2}$ and $\mathrm{MoO}_{3}{ }^{15,16}$. However by using this approach, the obtained films are polycrystalline in nature and incorporate small crystallite deposits, making it difficult to control the layers ${ }^{17,18}$. In this regard, the drop casting method has become a popular technique for depositing $\mathrm{MoS}_{2}$ layers onto a photonic surface due to simplicity, high stability, and reproducibility for larger scale production. Significant reports have already demonstrated the potential of this fabrication method, capable of generating highly stable, reproducible, and efficient thin films ${ }^{19-22}$.

In the development of photodetectors, 2D materials play a vital role in increasing the performance and reliability of the photodetector. In this regard, the number of $\mathrm{MoS}_{2}$ layers has a great impact on the performance of the photodetector. Mechanically exfoliated single, double, and triple layers of $\mathrm{MoS}_{2}$, labelled as 1L, 2L and 3L respectively are used to fabricate a phototransistor with the reported optical bandgap for the $1 \mathrm{~L}$ being $1.82 \mathrm{eV}, 1.65$ $\mathrm{eV}$ for the $2 \mathrm{~L}$ and $1.35 \mathrm{eV}$ for the $3 \mathrm{~L}$. The fabricated devices based on the $1 \mathrm{~L}$ and $2 \mathrm{~L}$ have high performance detection under green light illumination while the 3L based photodetector is only sensitive when illuminated by under the red wavelength region ${ }^{23}$. A reduced bandgap allows for the detection of light across a wider range of wavelength, and closer to the near infrared (NIR) region for $\mathrm{MoS}_{2}$ multiple layers thick. Similarly, ultraviolet (UV) to infrared (IR) photo-detection has been reported previously using thin films obtained by mechanical exfoliation ${ }^{24}$. Moreover, NIR photodetector has also been realized by multi-layer $\mathrm{MoS}_{2}$ flakes obtained via chemical exfoliation ${ }^{25}$. Recently, a broadband UVvisible-NIR (UV-Vis-NIR) photodetector using the aforementioned 2D material is reported, with a detectivity of $10^{10}$ Jones and a responsivity of $0.0084 \mathrm{~A} / \mathrm{W}$ that demonstrates good performance ${ }^{26}$.

In this work, a low-cost and highly efficient heterojunction photodetector device using $\mathrm{MoS}_{2}$ thin film deposited on the surface of a Si substrate by drop casting technique is proposed and demonstrated. The $\mathrm{n}-\mathrm{MoS}_{2} / \mathrm{p}$-Si photodetector device is characterized for its structural, optical, morphological, and compositional properties by Raman, photoluminescence (PL), field emission scanning electron microscope (FESEM) and energy dispersive X-ray (EDX) spectroscopy, respectively. The device is further characterized for its optoelectronic properties by current-voltage (IV) measurement system under illumination and dark conditions using a $785 \mathrm{~nm}$ near infrared (NIR) light source.

\section{Materials and Methods}

\subsection{Device Fabrication}

The MoS 2 based heterojunction photodetector device is fabricated employing the drop casting technique. The boron (B) doped crystalline silicon (c-Si) wafer is used as the p-type substrate in this device configuration. A thin layer of $\mathrm{MoS}_{2}$ serves as the n-type layer to establish a heterojunction with $\mathrm{p}-\mathrm{Si}$, as revealed in Figure 1.

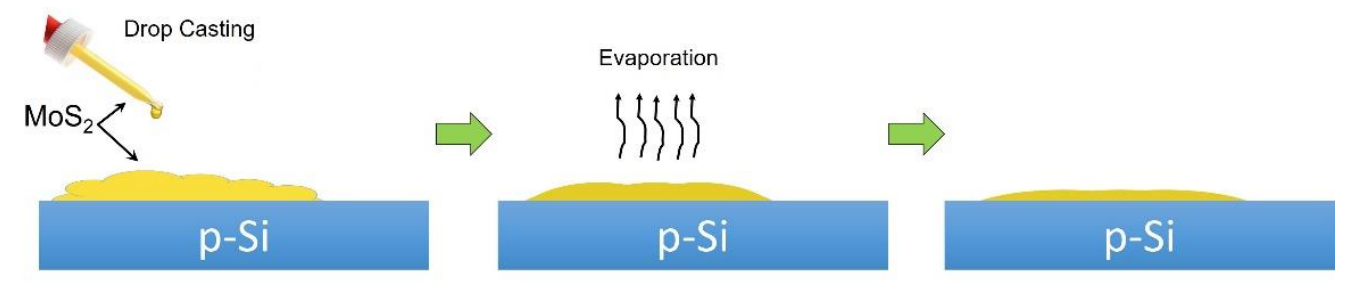

Figure 1. Schematic diagram of drop-casting thin $\mathrm{MoS}_{2}$ layer on top of p-Si substrate.

The pristine $\mathrm{MoS}_{2}$ nano-flakes are obtained from the Graphene Supermarket in an ethanol/deionized (DI) water solution. The pristine nano-flakes have a concentration of 18 
$\mathrm{mg} / \mathrm{L}$ with a lateral size of $100 \mathrm{~nm}-400 \mathrm{~nm}$. The $\mathrm{MoS}_{2}$ solution is first sonicated for $30 \mathrm{~min}$ at $80{ }^{\circ} \mathrm{C}$ and at the same time the p-Si wafer is cut into $3 \mathrm{~cm} \times 2 \mathrm{~cm}$ rectangular shape. The substrate on the other hand is cleansed ultrasonically using isopropyl alcohol (IPA) and deionized (DI) water for 20 and 30 min respectively to eliminate any contaminants from the surface before being dried using pure nitrogen $\left(\mathrm{N}_{2}\right)$ gas. Subsequently, a hotplate is heated to $60^{\circ} \mathrm{C}$ and the substrate is placed on top of it for pre-deposition heating for $5 \mathrm{~min}$. Approximately $5 \mu \mathrm{l}$ of the $\mathrm{MoS}_{2}$ solution using a micropipette is drop casted onto the surface of the p-Si substrate. After about $5 \mathrm{~min}$, the sample is removed from the hotplate and kept in a desiccator for $24 \mathrm{hrs}$. to dry naturally. Finally, the electrodes are formed by silver (Ag) paste deposited on both the $\mathrm{p}-\mathrm{Si}$ and $\mathrm{n}-\mathrm{MoS}_{2}$ surfaces to form the conductive contacts. The schematic diagram of the fabricated heterojunction device is presented in Figure 2 (a).

(a)

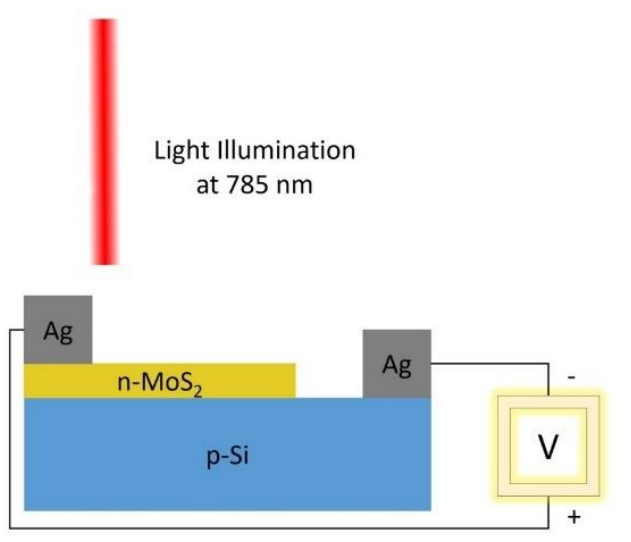

(b)

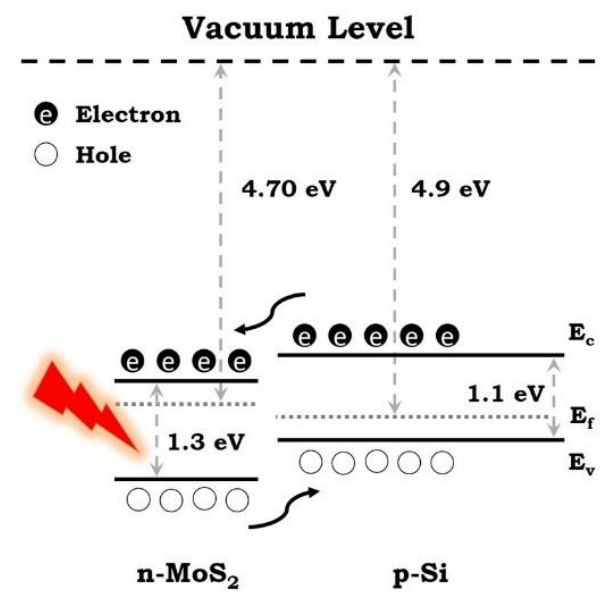

Figure 2. (a) Schematic diagram of fabricated n-MoS $2 / \mathrm{p}-\mathrm{Si}$ heterojunction photodetector. (b) Energy band diagram of $\mathrm{n}-\mathrm{MoS}_{2} / \mathrm{p}-\mathrm{Si}$ in isolated state.

\subsection{Characterization $\mathcal{E}$ Device Measurement}

The surface morphology of the fabricated device is obtained using a JEOL JSM7600F FESEM, while compositional analysis and mapping are performed using an Oxford Instruments EDX. An inVia confocal Raman microscope with $532 \mathrm{~nm}$ illumination is used to obtain the elemental composition of the heterojunction device. The optoelectronic characteristics of the heterojunction n-MoS2/p-Si photodetector is measured under $785 \mathrm{~nm}$ illumination at the NIR region. A Keithley 2410 - $1100 \mathrm{~V}$ SourceMeter ${ }^{\circledR}$ is used to obtain the $I V$ curves between $-10 \mathrm{~V}$ to $10 \mathrm{~V}$. The distance from the surface of photodetector to the laser source is kept constant at $2 \mathrm{~cm}$ and the effective area (A) is calculated to be 0.0706 $\mathrm{cm}^{2}$. The power densities of the illumination source are varied $\left(6.06 \mathrm{~mW} / \mathrm{cm}^{2}, 6.99\right.$ $\mathrm{mW} / \mathrm{cm}^{2}, 8.05 \mathrm{~mW} / \mathrm{cm}^{2}$ and $9.57 \mathrm{~mW} / \mathrm{cm}^{2}$ ). The photodetector's time-based responses are collected using a Yokogawa DLM2054 mixed signal oscilloscope. The bias voltages ( $\left.\mathrm{V}_{\mathrm{B}}\right)$ are varied from $1.0 \mathrm{~V}$ to $10.0 \mathrm{~V}$ with an interval of $1.0 \mathrm{~V}$. The Stanford Research Systems' DS345 - $30 \mathrm{MHz}$ synthesized function generator (SFG) is used to modulate frequency signals from $1 \mathrm{~Hz}$ to $20 \mathrm{kHz}$ for testing the photodetector. All the measurements are obtained at the ambient conditions.

\section{Results \& Discussion}

\subsection{Raman \& Photoluminescence}

Figure 3 (a) provides the Raman spectra of the fabricated heterojunction n-MoS $2 / \mathrm{p}-\mathrm{Si}_{\mathrm{i}}$ photodetector from $200 \mathrm{~cm}^{-1}$ to $900 \mathrm{~cm}^{-1}$. From the figure, three dominant peaks are observed, with the most intense peak witnessed at $520.40 \mathrm{~cm}^{-1}$. This peak is attributed to c-Si that is present in the substrate. Another two peaks are noticed at $382.42 \mathrm{~cm}^{-1}$ and 407.97 $\mathrm{cm}^{-1}$ which is the in-plane $\mathrm{E}^{1}{ }_{2 \mathrm{~g}}$ phonon mode of $\mathrm{MoS}_{2}$ whilst the second peak is the A1g out- 
plane mode. These two peaks confirm the successful development of $\mathrm{MoS}_{2}$ thin film ${ }^{27}$. The distance $(\Delta)$ between the modes is calculated to be nearly $25.55 \mathrm{~cm}^{-1}$ with the weak van der Waals interlayer forces between the sulfur (S) atoms in particular resulting in the lattice vibrations. These findings are consistent with previous research ${ }^{28}$. The photoluminescence (PL) spectra of the $\mathrm{MoS}_{2}$ is given in Figure 3 (b) and from this the energy bandgap is calculated. A direct bandgap of $2.01 \mathrm{eV}$ is obtained, indicating the successful deposition of a n-type $\mathrm{MoS}_{2}$ thin film from the drop casting technique ${ }^{29,30}$.

(a)

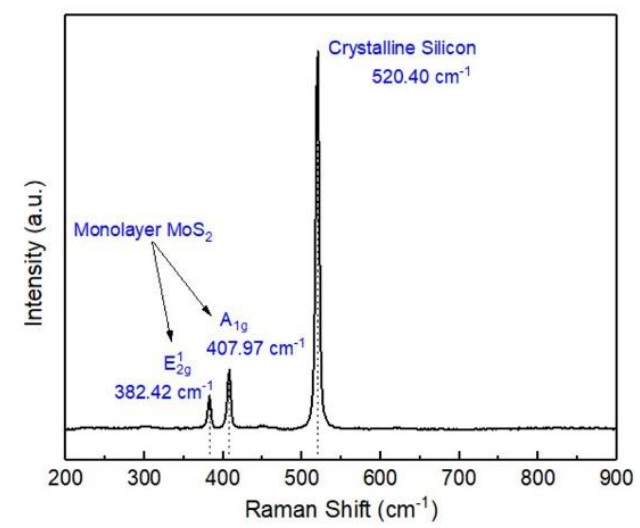

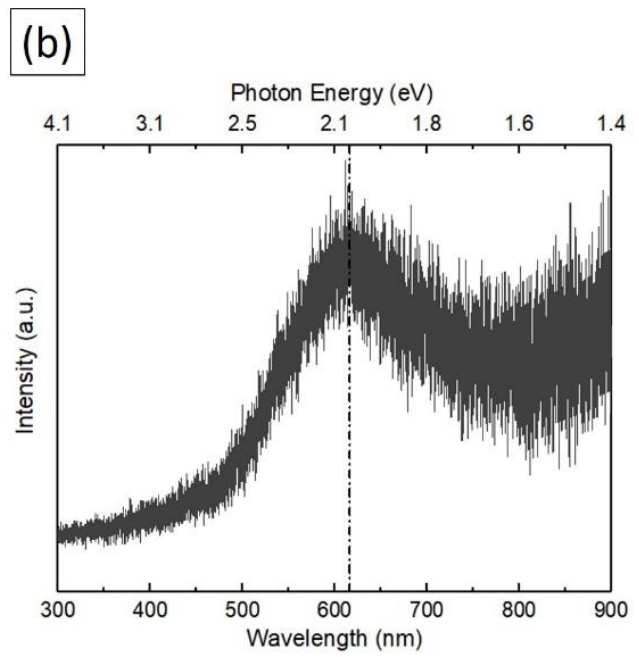

Figure 3. (a) Raman spectra of heterojunction n-MoS2/p-Si photodetector device and (b) PL spectra with respect to energy bandgap of $\mathrm{MoS}_{2}$ thin film.

\subsection{FESEM \& EDX}

The surface morphology of the $\mathrm{MoS}_{2}$ thin film grown on top of the p-Si substrate is presented in Figure 4 (a). From the figure, it can be observed that the nano-flakes formed have a general length of 2.0 microns and width of 0.7 micron, together with several nanoparticles of $100 \mathrm{~nm}$ to $1 \mu \mathrm{m}$ diameter. The surface of the film appears rough and inhomogeneous which is attributed to the coffee ring effect that normally occurs during the drop casting of most materials. This effect is unavoidable and is faced almost constantly as reported by many other research groups ${ }^{31}$. Elemental compositional analysis obtained by EDX is depicted in Figure 4 (b) for fabricated device. The weight and atomic percentages of present elements are tabulated as the inset in Figure $4(\mathrm{~b})$, where the presence of $\mathrm{C}, \mathrm{O}$, $\mathrm{Mg}, \mathrm{Na}, \mathrm{Al}, \mathrm{K}, \mathrm{Si}, \mathrm{Ca}, \mathrm{S}$ and Mo can be confirmed. The normalized atomic \% ratio of S/Mo is calculated to be 2.02 and confirms the non-stoichiometric layer growth of the thin $\mathrm{MoS}_{2}$ film on top of the Si substrate ${ }^{32}$.
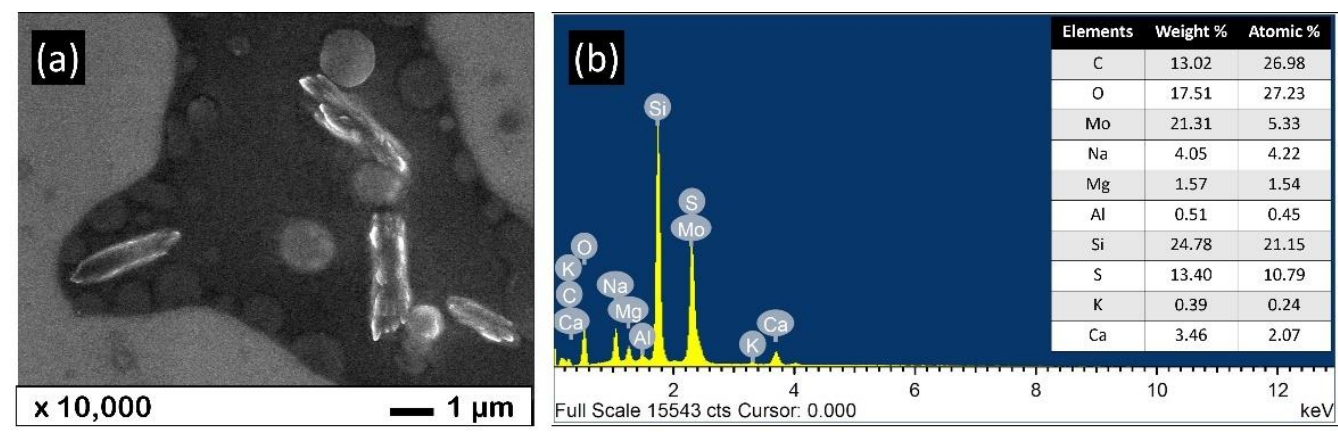

Figure 4. (a) Surface morphology of thin $\mathrm{MoS}_{2}$ film drop casted on top of Si wafer and (b) Elemental compositional analysis of heterojunction n-MoS $2 / p-S i$ photodetector by EDX.

\subsection{Mapping}


The distribution of Mo, S, O and Si elements in the heterojunction n-MoS2/p-Si photodetector is acquired from EDX mapping analysis. The scanning results are given in Figure 5, with each element classified in different colors indicate its distribution in the device. The red and green colors are used to represent the scattering of the Mo and S elements on the scanned surface, whereas the blue color and grey colors show the distribution of the $\mathrm{O}$ and Si.

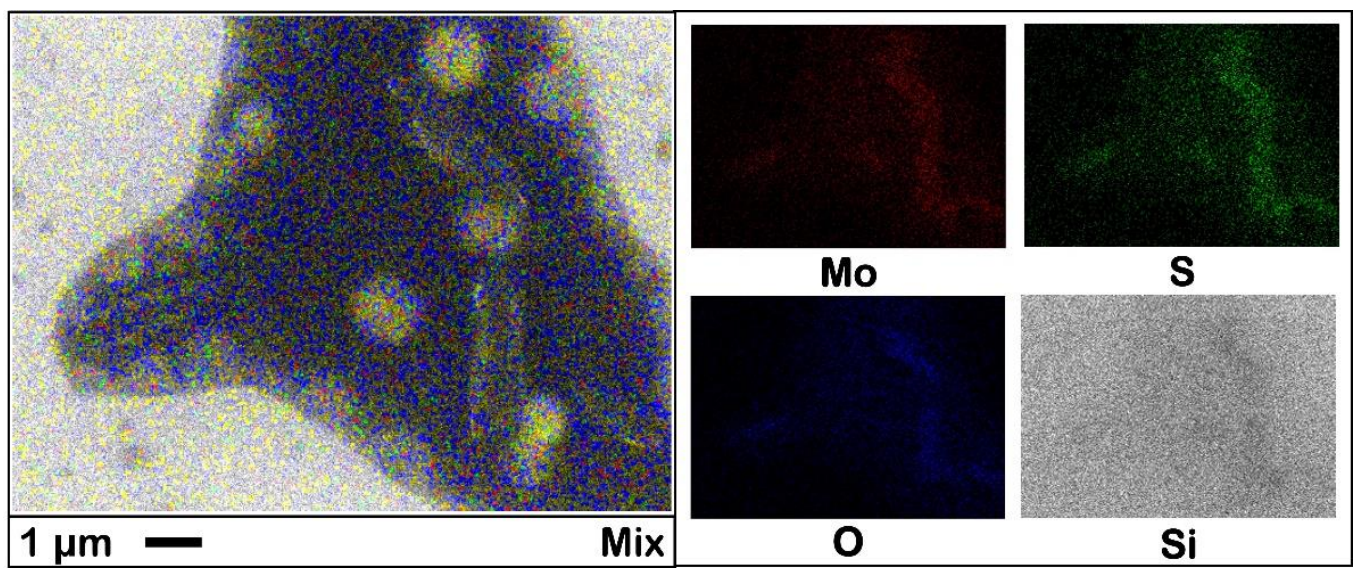

Figure 5. Elemental distribution mapping of heterojunction n-MoS2/p-Si photodetector.

\subsection{Measurement}

$I V$ measurements are performed to analyze the opto-electronic properties of the heterojunction n-MoS $2 / \mathrm{p}-\mathrm{Si}$ photodetector at $785 \mathrm{~nm}$ with NIR illumination source in the light and dark conditions. The photodetector is illuminated at various power densities e.g., 6.06 $\mathrm{mW} / \mathrm{cm}^{2}, 6.99 \mathrm{~mW} / \mathrm{cm}^{2}, 8.05 \mathrm{~mW} / \mathrm{cm}^{2}$ and $9.57 \mathrm{~mW} / \mathrm{cm}^{2}$ to attain the $I V$ curves. Figure 6 (a) shows the logarithmic $I V$ curves obtained under dark and illuminated conditions within the bias voltage range of $-10 \mathrm{~V}$ to $10 \mathrm{~V}$. In Figure $6(\mathrm{~b})$, the linear $I V$ curves can be observed from $-10 \mathrm{~V}$ to $10 \mathrm{~V}$ for both dark and illuminated conditions and confirms the successful establishment of a p-n junction between the p-Si and n-MoS layers. The threshold voltage is observed to be around $1.5 \mathrm{~V}$ in the forward biased region and around -1.0 $\mathrm{V}$ in the reverse biased region. This indicates that the fabricated device can only operate at $1.5 \mathrm{~V}$ and above in the forward biased region and $-1.0 \mathrm{~V}$ and below in the reverse biased region under illumination and dark conditions. Figure $6(\mathrm{~d})$ represents the $I V$ curves of the fabricated device in the reverse biased region from $-5 \mathrm{~V}$ to $0 \mathrm{~V}$ while Figure 6 (e) shows the $I V$ curves in the forward biased region from $0 \mathrm{~V}$ to $5 \mathrm{~V}$. The current is also found to be linear with respect to the bias voltages in the reverse and forward biased regions, thus confirming the ability of the fabricated heterojunction photodetector to operate at two different regions.

Figure 2 (b) shows a schematic band diagram to help in understanding the operational mechanism of the fabricated heterojunction n-MoS $/ \mathrm{p}-\mathrm{Si}$ photodetector device. A built-in potential at the interface enables the separation of photocarriers generated as the device is exposed to a light source at the wavelength of $785 \mathrm{~nm}$ in the light spectrum, resulting in the formation of a photo-response. The barrier height is shortened, and the separation of holes and electrons is stimulated as the voltage drop is applied between the electrodes. The valence band electrons are influenced to the conduction band. The p-type layer ( $\mathrm{p}$-Si) serves as the hole collector, while the n-type layer (n-MoS $)$ passes the electrons from the higher energy band to the lower energy band. The responsivity $(R)$ of the photodetector is measured from Equation 1, where Iillumination is the current under various illumination conditions, $I_{\text {dark }}$ is the dark current, $P_{\text {laser }}$ is the power of the laser source and $A$ is the effective area of the $785 \mathrm{~nm}$ incident light $19,21,33$. Figure $6(\mathrm{f})$ shows the relationship between the maximum value of $R$ as calculated for various incident laser power densities at a $10 \mathrm{~V}$ bias voltage. 


$$
R=\frac{I_{\text {illumination }}-I_{\text {dark }}}{P_{\text {laser }} \times A}
$$

The detectivity $\left(D^{*}\right)$ of the fabricated device can be calculated from Equation 2, where $R$ is the function of $D^{* 21,33}$. Figure 6 (f) shows the power densities with their dependency on $D^{*}$. A linear function is evident for both $R$ and $D^{*}$ with respect to power densities. The maximum value of $R$ is computed to be $0.52 \mathrm{~A} / \mathrm{W}$ and $D^{*}$ as $4.08 \times 10^{10}$ Jones for an incident power density of $9.57 \mathrm{~mW} / \mathrm{cm}^{2}$.

$$
D^{*}=R \sqrt{\frac{A}{2 q I_{\text {dark }}}}
$$

The correlation of $D^{*}$ in regard to DC bias voltage in the span of $0 \mathrm{~V}$ to $10 \mathrm{~V}$ can be pragmatic from the Figure 6 (c) where it is calculated for various illuminated power densities in the NIR region. It is very interesting to observe the detectivity trend of fabricated device, the value of $D^{*}$ increases with the increase in bias voltages until it approached 4.8 $\mathrm{V}$ to $5 \mathrm{~V}$ where the maximum value of $D^{*}$ is computed. After $5 \mathrm{~V}$, the value of $D^{*}$ decreases gradually while a slight rise is observed after $9 \mathrm{~V}$.

Figure 7 signifies the time dependent current responses of various power densities illuminated under $785 \mathrm{~nm}$ at DC bias voltages ( $3 \mathrm{~V}, 5 \mathrm{~V}$ and $10 \mathrm{~V})$. Figure 7 (a) indicates the response times for a power density of $6.06 \mathrm{~mW} / \mathrm{cm}^{2}$, Figure 7 (b) for a power density of $6.99 \mathrm{~mW} / \mathrm{cm}^{2}$, Figure 7 (c) for a power density of $8.05 \mathrm{~mW} / \mathrm{cm}^{2}$ and Figure 7 (d) for a power density of $9.57 \mathrm{~mW} / \mathrm{cm}^{2}$. The modulation frequency is set to $1 \mathrm{~Hz}$ throughout the measurement.

(a)

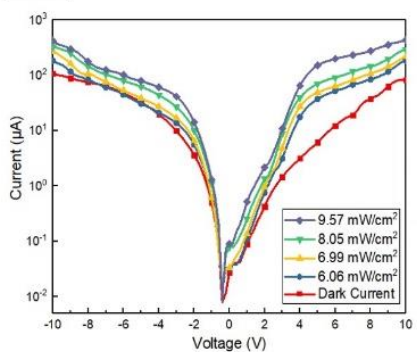

(d)

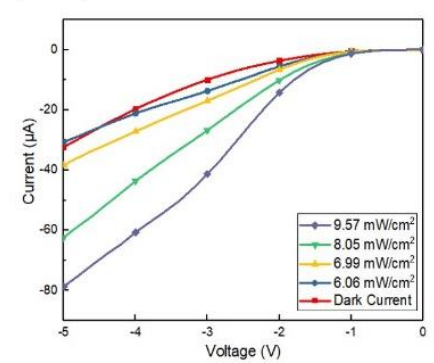

(b)

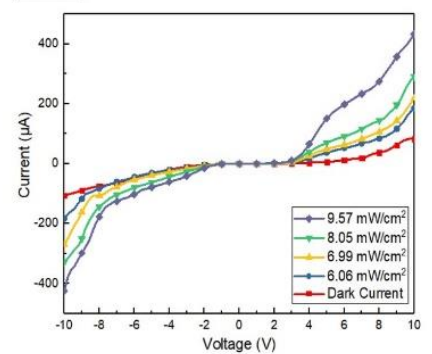

(e)

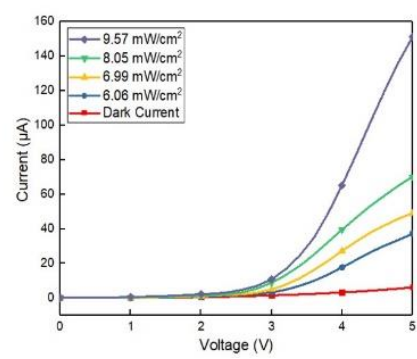

(c)

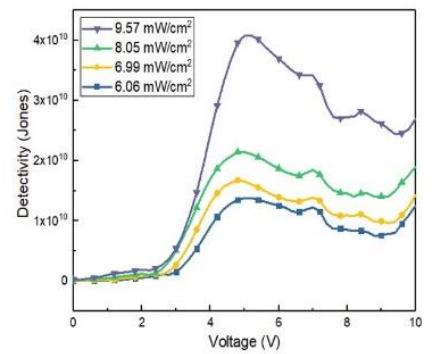

(f)

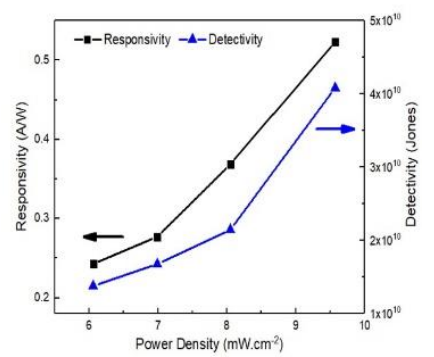

Figure 6. (a) Logarithmic $I V$ curves of heterojunction n-MoS2/p-Si photodetector under light and dark conditions from $-10 \mathrm{~V}$ to $10 \mathrm{~V}$ bias voltage, (b) Linear $I V$ curves under dark and illumination conditions from $-10 \mathrm{~V}$ to $10 \mathrm{~V}$ bias voltage, (c) Detectivity as a function of DC bias voltage from $0 \mathrm{~V}$ to $10 \mathrm{~V}$ for various power densities i.e., $6.06 \mathrm{~mW} / \mathrm{cm}^{2}, 6.99 \mathrm{~mW} / \mathrm{cm}^{2}, 8.05 \mathrm{~mW} / \mathrm{cm}^{2}$ and 9.57 $\mathrm{mW} / \mathrm{cm}^{2}$ at $785 \mathrm{~nm}$, (d) Partially magnified $I V$ curves in the reverse biased region from $-5 \mathrm{~V}$ to $0 \mathrm{~V}$ under dark and illumination conditions, (e) Partially magnified $I V$ curves in the forward biased region from $0 \mathrm{~V}$ to $5 \mathrm{~V}$ under dark and illumination conditions and (f) Power density dependent responsivity and detectivity of fabricated heterojunction photodetector device illuminated in the NIR region. 
(a)

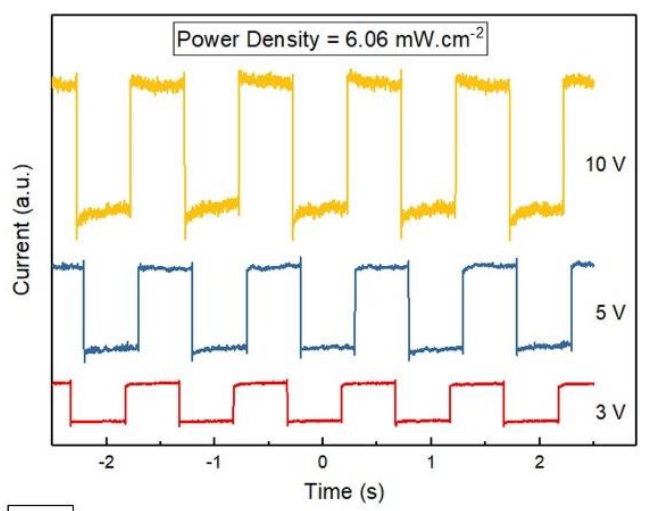

(c)

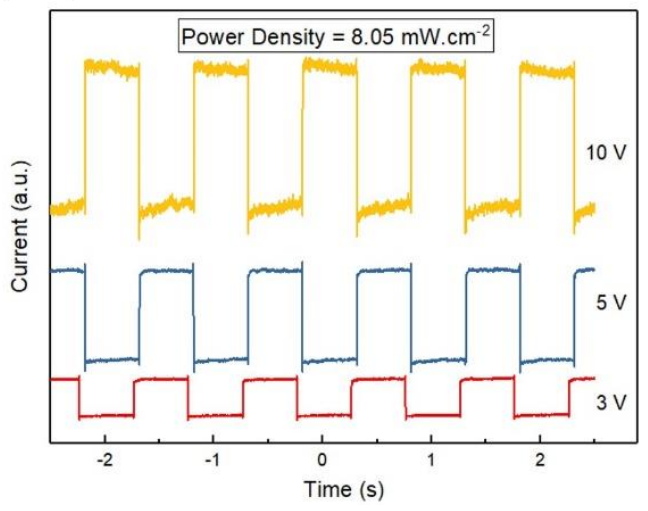

(b)

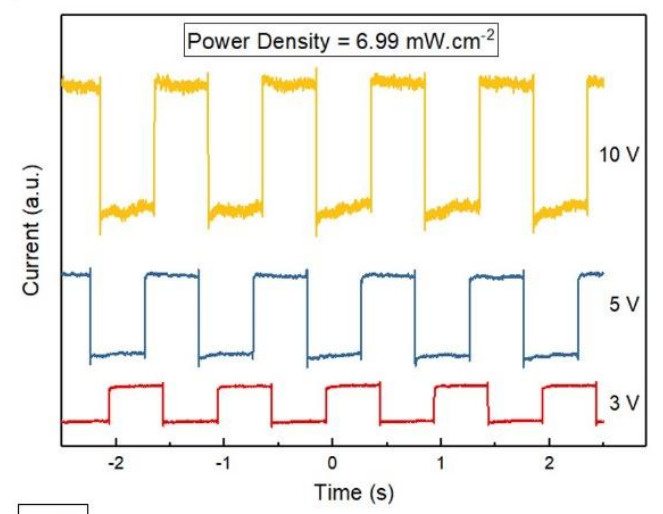

(d)

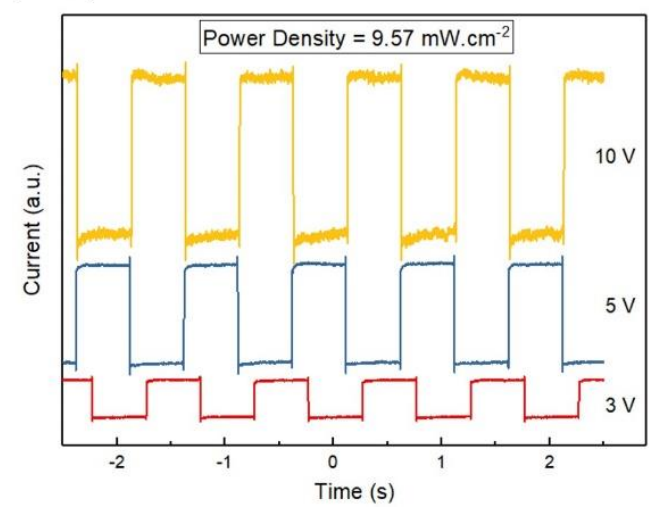

Figure 7. Time dependent current responses of fabricated n-MoS $/ \mathrm{p}$-Si heterojunction photodetector functioned at DC bias voltages of $3 \mathrm{~V}, 5 \mathrm{~V}$ and $10 \mathrm{~V}$ in the NIR region with various power densities (a) $6.06 \mathrm{~mW} / \mathrm{cm}^{2}$, (b) $6.99 \mathrm{~mW} / \mathrm{cm}^{2}$, (c) $8.05 \mathrm{~mW} / \mathrm{cm}^{2}$ and (d) $9.57 \mathrm{~mW} / \mathrm{cm}^{2}$.

Table 1 shows the rise and fall times of the fabricated heterojunction photodetector when illuminated at $785 \mathrm{~nm}$ for various intensities at bias voltages (DC) of $3 \mathrm{~V}, 5 \mathrm{~V}$ and 10 $\mathrm{V}$. A decreasing trend is observed when comparing the rise time of the various power densities with the increase in the bias voltages (DC) from $3 \mathrm{~V}$ to $10 \mathrm{~V}$ except for the intensity $9.57 \mathrm{~mW} / \mathrm{cm}^{2}$ where no specific trend is observed. In the case of fall time, a non-linear trend is observed with the rise in bias voltages and the same movement is found when compared among various power densities. The rise time among various power densities has an increasing pattern within the same bias voltage except for $5 \mathrm{~V}$.

Table 1. Rise \& fall times of various power densities illuminated at $785 \mathrm{~nm}$ for heterojunction $\mathrm{n}-\mathrm{MoS}_{2} / \mathrm{p}-\mathrm{Si}$ photodetector at $3 \mathrm{~V}, 5 \mathrm{~V}$ and $10 \mathrm{~V}$ DC bias voltages.

\section{Power Density}

\section{Bias Voltage} $3 \mathrm{~V}$
$5 \mathrm{~V}$

$10 \mathrm{~V}$ 


\begin{tabular}{ccccccccc}
\cline { 2 - 3 } \cline { 7 - 8 } & $\begin{array}{c}\text { Rise Time } \\
(\mathbf{m s})\end{array}$ & $\begin{array}{c}\text { Fall Time } \\
(\mathbf{m s})\end{array}$ & & $\begin{array}{c}\text { Rise Time } \\
(\mathbf{m s})\end{array}$ & $\begin{array}{c}\text { Fall Time } \\
(\mathbf{m s})\end{array}$ & & $\begin{array}{c}\text { Rise Time } \\
(\mathbf{m s})\end{array}$ & $\begin{array}{c}\text { Fall Time } \\
(\mathbf{m s})\end{array}$ \\
\hline $6.06 \mathrm{~mW} / \mathrm{cm}^{2}$ & 8.72 & 1.45 & & 2.06 & 1.39 & & 1.85 & 1.44 \\
$6.99 \mathrm{~mW} / \mathrm{cm}^{2}$ & 2.07 & 1.40 & & 1.87 & 1.44 & & 1.82 & 1.31 \\
$8.05 \mathrm{~mW} / \mathrm{cm}^{2}$ & 2.05 & 1.41 & & 1.96 & 1.45 & & 1.78 & 1.45 \\
$9.57 \mathrm{~mW} / \mathrm{cm}^{2}$ & 1.92 & 1.44 & & 2.03 & 1.48 & & 1.77 & 1.38 \\
\hline
\end{tabular}

Figure 8 (a) gives the time dependent responses of the generated current at several bias voltages (DC) from $1 \mathrm{~V}$ to $10 \mathrm{~V}$ with an interval of $1 \mathrm{~V}$ at modulation frequency of 1 $\mathrm{Hz}$ under $785 \mathrm{~nm}$ illumination. The results obtained from the figure are comparable to the $I V$ measurement, and it can be seen form the $I V$ curves that the threshold voltage level is between $1 \mathrm{~V}$ to $2 \mathrm{~V}$ in the forward biased region. The same can be noticed from the time dependent responses where there is no response recorded at $1 \mathrm{~V}$. Overall, there is an increasing trend observed as the bias voltage increases. The rise and fall times are calculated and presented in Table 2. The shortest rise time observed is $1.47 \mathrm{~ms}$ with a fall time of 1.09 $\mathrm{ms}$ under a $2 \mathrm{~V}$ bias voltage. The maximum rise time of $2.02 \mathrm{~ms}$ is seen for a bias voltage of $6 \mathrm{~V}$. In the range of $4 \mathrm{~V}$ to $6 \mathrm{~V}$, the rise time and fall times are quite close in terms of their numerical values which indicates the saturation level of the device's detectivity, and it is in good agreement with the calculated values of $D^{*}$ as presented in Figure 6 (c).

(a)

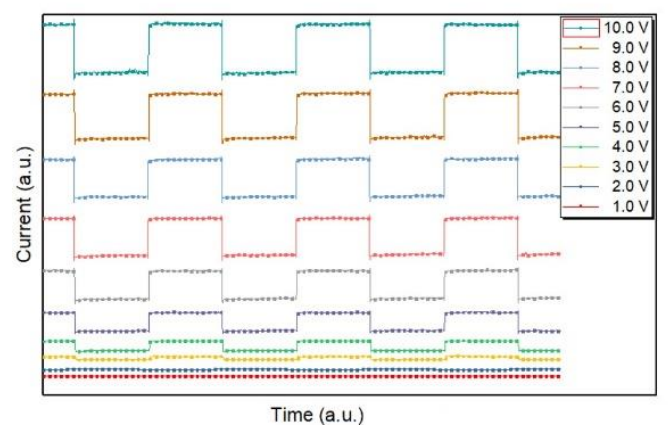

(c)

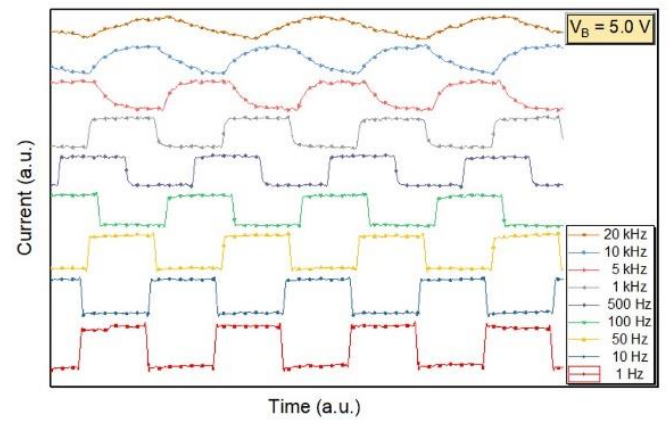

(b)

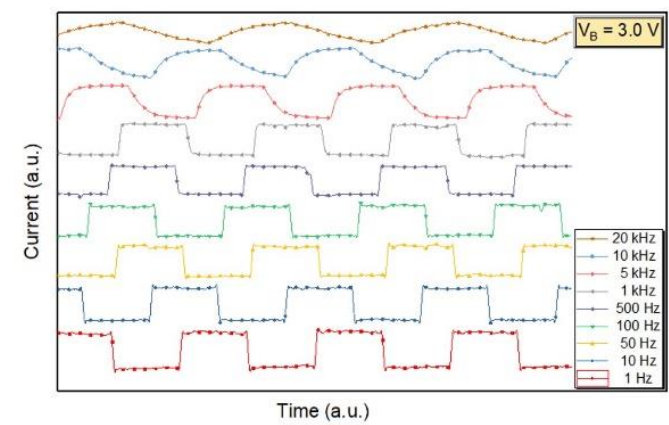

(d)

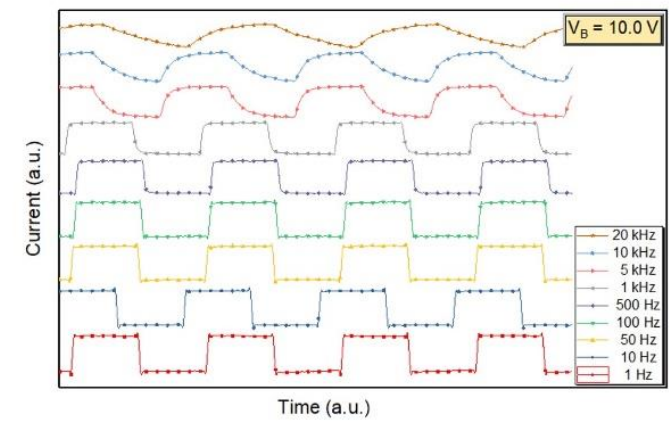

Figure 8. (a) Time dependent illuminated current responses in the NIR region at $785 \mathrm{~nm}$ illumination at numerous DC bias voltages from $1 \mathrm{~V}$ to $10 \mathrm{~V}$ with an interval of $1 \mathrm{~V}$, (b) Time dependent current responses for various modulation frequencies from 1 to $20 \mathrm{k} \mathrm{Hz}$ under illumination with red laser source for fabricated heterojunction n-MoS $/ \mathrm{p}-\mathrm{Si}$ photodetector at bias voltages, $\mathrm{V}_{\mathrm{B}}=3 \mathrm{~V}$, (c) $\mathrm{V}_{\mathrm{B}}=5.0 \mathrm{~V}$ and (d) $\mathrm{V}_{\mathrm{B}}=10.0 \mathrm{~V}$.

Table 2. Rise time and fall time calculated from the time dependent current responses for numerous bias voltages from $1 \mathrm{~V}$ to $10 \mathrm{~V}$ for $\mathrm{n}-\mathrm{MoS}_{2} / \mathrm{p}-\mathrm{Si}$ heterojunction photodetector.

\begin{tabular}{ccc}
\hline $\begin{array}{c}\text { DC Bias Voltage } \\
(\mathrm{V})\end{array}$ & $\begin{array}{c}\text { Rise Time } \\
(\mathrm{ms})\end{array}$ & $\begin{array}{c}\text { Fall Time } \\
(\mathrm{ms})\end{array}$ \\
\hline 1.0 & - & - \\
2.0 & 1.47 & 1.09
\end{tabular}




\begin{tabular}{ccc}
3.0 & 1.59 & 1.38 \\
4.0 & 1.94 & 1.41 \\
5.0 & 1.96 & 1.41 \\
6.0 & 2.02 & 1.40 \\
7.0 & 1.88 & 1.38 \\
8.0 & 1.90 & 1.39 \\
9.0 & 1.87 & 1.45 \\
10.0 & 1.88 & 1.47 \\
\hline
\end{tabular}

The time dependent current responses for a variety of modulation frequencies i.e. 1 $\mathrm{Hz}, 10 \mathrm{~Hz}, 50 \mathrm{~Hz}, 100 \mathrm{~Hz}, 500 \mathrm{~Hz}, 1 \mathrm{kHz}, 5 \mathrm{kHz}, 10 \mathrm{kHz}$ and $20 \mathrm{kHz}$ are given in Figure 8 (b) for bias voltage (DC) of $3.0 \mathrm{~V}$, Figure 8 (c) for $5.0 \mathrm{~V}$ and Figure 8 (d) for $10.0 \mathrm{~V}$ under $785 \mathrm{~nm}$ illumination. The rise and fall times are computed and tabulated in Table 3 . The minimum rise time is observed to be $15.52 \mathrm{~ms}$ at $3.0 \mathrm{~V}, 17.79 \mathrm{~ms}$ at $5.0 \mathrm{~V}$ and $16.30 \mathrm{~ms}$ at $10.0 \mathrm{~V}$ for $20 \mathrm{kHz}$ frequency. The minimum fall time is seen to be $15.04 \mathrm{~ms}$ at $3.0 \mathrm{~V}, 14.16$ $\mathrm{ms}$ at $5.0 \mathrm{~V}$ and $14.58 \mathrm{~ms}$ at $10.0 \mathrm{~V}$ for $20 \mathrm{kHz}$ modulation frequency. A linear decreasing trend is observed towards higher modulation frequencies for both rise and fall times.

Table 3. Rise and fall times calculated from the time dependent current responses at a variety of modulation frequencies from 1 to $20 \mathrm{k} \mathrm{Hz}$ under red laser source illuminated at $785 \mathrm{~nm}$ for $3 \mathrm{~V}, 5 \mathrm{~V}$ and $10 \mathrm{~V}$ DC bias voltages.

\begin{tabular}{|c|c|c|c|c|c|c|}
\hline \multirow{3}{*}{$\begin{array}{c}\text { Frequency } \\
(\mathrm{Hz})\end{array}$} & \multicolumn{6}{|c|}{ Bias Voltage (DC) } \\
\hline & \multicolumn{2}{|c|}{$3 \mathrm{~V}$} & \multicolumn{2}{|c|}{$5 \mathrm{~V}$} & \multicolumn{2}{|c|}{$10 \mathrm{~V}$} \\
\hline & $\begin{array}{c}\text { Rise Time } \\
\text { (ms) }\end{array}$ & $\begin{array}{l}\text { Fall Time } \\
\text { (ms) }\end{array}$ & $\begin{array}{c}\text { Rise Time } \\
\text { (ms) }\end{array}$ & $\begin{array}{l}\text { Fall Time } \\
\text { (ms) }\end{array}$ & $\begin{array}{c}\text { Rise Time } \\
\text { (ms) }\end{array}$ & $\begin{array}{l}\text { Fall Time } \\
\text { (ms) }\end{array}$ \\
\hline 1 & 328.43 & 381.04 & 310.21 & 376.59 & 359.4 & 372.22 \\
\hline 10 & 210.8 & 239.67 & 249.73 & 297.54 & 204.46 & 261.62 \\
\hline 50 & 100.32 & 183.14 & 124.24 & 198.44 & 117.21 & 214.05 \\
\hline 100 & 20.68 & 35.09 & 32.37 & 53.57 & 31.82 & 45.10 \\
\hline 500 & 16.68 & 22.50 & 19.58 & 25.17 & 19.25 & 23.78 \\
\hline $1 \mathrm{k}$ & 16.33 & 15.93 & 19.56 & 15.45 & 17.06 & 15.62 \\
\hline $5 \mathrm{k}$ & 16.15 & 15.87 & 18.29 & 14.28 & 17.5 & 15.22 \\
\hline $10 \mathrm{k}$ & 15.72 & 15.64 & 17.93 & 14.27 & 16.95 & 15.07 \\
\hline $20 \mathrm{k}$ & 15.52 & 15.04 & 17.79 & 14.16 & 16.30 & 14.58 \\
\hline
\end{tabular}

The performance of the proposed photodetector in this work against other MoS 2 heterojunction structure-based devices is tabulated in Table 4 . From the results, it can be seen that the proposed device is highly responsive in the NIR region with $D^{*}$ calculated as 4.08 $x 10^{10}$ Jones. Therefore, the proposed photodetector structure which is fabricated using drop casting the nanoparticle solution onto the surface of the substrate can realize the development of $\mathrm{MoS}_{2}$ applications in sensors, detectors, photovoltaic as well as photodetectors at large scales with lower costs.

Table 4. Performance parameters comparison of several $\mathrm{MoS}_{2}$ based heterojunction photodetector devices.

\begin{tabular}{llccc}
\hline \multicolumn{1}{c}{ Structure } & \multicolumn{1}{c}{ Methodology } & R (A/W) & D $^{*}$ (Jones) & Reference \\
\hline n-MoS $2 / \mathbf{p}-S i$ & Drop Casting & $\mathbf{0 . 5 2}$ & $\mathbf{4 . 0 8} \mathbf{~ 1 0} \mathbf{1 0}^{\mathbf{1 0}}$ & This work \\
$\mathrm{MoS}_{2} / \mathrm{Sapphires}$ & CVD & 0.0084 & $10^{10}$ & 26 \\
$\mathrm{MoS}_{2} / \mathrm{c}-\mathrm{Si}$ & Sputtering & 0.3 & $10^{13}$ & 34 \\
$\mathrm{a}-\mathrm{Si} / \mathrm{MoS}_{2}$ & Mechanical Exfoliation & 0.21 & - & 35 \\
$\mathrm{p}-\mathrm{MoS}_{2} / \mathrm{n}-\mathrm{Si}$ & Mechanical Exfoliation & 7.2 & $10^{9}$ & 36
\end{tabular}




\begin{tabular}{|c|c|c|c|c|}
\hline $\mathrm{MoS}_{2} /$ Flat GaN & CVD and Transfer & 0.16 & - & 37 \\
\hline $\mathrm{MoS}_{2} /$ Patterned GaN & CVD and Transfer & 0.25 & $5.6 \times 10^{8}$ & 37 \\
\hline $\mathrm{Au}-\mathrm{NPS} / \mathrm{MoS}_{2}$ & Hydrothermal & 0.04603 & - & 38 \\
\hline
\end{tabular}

\section{Conclusion}

In this work, a highly efficient heterojunction n-MoS $/ \mathrm{p}-\mathrm{Si}$ photodetector is fabricated, and its performance demonstrated. Characterization analysis of the fabricated device gives Raman shifts at $382.42 \mathrm{~cm}^{-1}$ and $407.97 \mathrm{~cm}^{-1}$, validating the presence of $\mathrm{MoS}_{2}$ thin film that is deposited using a cost-effective and simple drop casting method. The normalized S/Mo ratio is found to be 2.02 with a direct bandgap of $2.01 \mathrm{eV}$ for an inhomogeneous and non-stoichiometric $\mathrm{MoS}_{2}$ layer. The photodetector is revealed to various light intensities at $785 \mathrm{~nm}$, with the threshold voltages found to be at $1.5 \mathrm{~V}$ in forward bias region and $-1.0 \mathrm{~V}$ in the reverse bias region. The maximum value of $R$ is calculated to be $0.52 \mathrm{~A} / \mathrm{W}$ and $D^{*}$ as $4.08 \times 10^{10}$ Jones for an incident power intensity of $9.57 \mathrm{~mW} / \mathrm{cm}^{2}$. The minimum rise time is given as $1.77 \mathrm{~ms}$ for an incident laser power of $9.57 \mathrm{~mW} / \mathrm{cm}^{2}$ and minimum fall time as $1.31 \mathrm{~ms}$ for an incident power density of $6.99 \mathrm{~mW} / \mathrm{cm}^{2}$ at $10 \mathrm{~V} \mathrm{DC}$ bias voltage. The minimum rise time is calculated to be $15.52 \mathrm{~ms}$ at $3.0 \mathrm{~V}$ for $20 \mathrm{kHz}$ frequency and the minimum fall time is noted to be $14.16 \mathrm{~ms}$ at $5.0 \mathrm{~V}$ for $20 \mathrm{kHz}$ modulation frequency. The proposed results would have significant applications in optical devices such as sensors, detectors, photovoltaic as well as for the large-scale manufacturing of low-cost photodetectors.

Author Contributions: Conceptualization, H.R.; methodology, H.R.; validation, N.A. and A.A.A.B.; formal analysis, H.R.; investigation, H.R.; resources, H.A.; data curation, H.R.; writing-original draft preparation, H.R.; writing - review and editing, N.A. and A.A.A.B.; visualization, H.R.; supervision, M.I.R.; project administration, M.I.R.; funding acquisition, N.A. and M.I.R. All authors have read and agreed to the published version of the manuscript.

Funding: This research was funded by Universiti Kebangsaan Malaysia, grant number MI-2020-002 (Modal Insan), Ministry of Science, Technology \& Innovation (MOSTI), grant number IF0419IF1082 and the APC was funded by Universiti Kebangsaan Malaysia.

Institutional Review Board Statement: Not applicable.

Informed Consent Statement: Not applicable.

Conflicts of Interest: The authors declare no conflict of interest.

\section{References}

1. Kanaujiya, N.; Anupam; Golimar, K.; Pandey, P. C.; Jyoti; Varma, G. In Investigating NO2 gas sensing behavior of flower-like MoS2 and rGO based nano-composite, AIP Conference Proceedings, AIP Publishing: 2018; p 030142.

2. Bai, F.; Qi, J.; Li, F.; Fang, Y.; Han, W.; Wu, H.; Zhang, Y., A High-Performance Self-Powered Photodetector Based on Monolayer $\mathrm{MoS}_{2} /$ Perovskite Heterostructures. Advanced Materials Interfaces 2018, 5 (6), 1701275.

3. Yao, K.; Xu, Z.; Li, Z.; Liu, X.; Shen, X.; Cao, L.; Huang, J., Synthesis of Grain-like MoS2 for High-Performance SodiumIon Batteries. ChemSusChem 2018, 11 (13), 2130-2137.

4. Xu, Z.-Q.; Zhang, Y.; Wang, Z.; Shen, Y.; Huang, W.; Xia, X.; Yu, W.; Xue, Y.; Sun, L.; Zheng, C., Atomically thin lateral p-n junction photodetector with large effective detection area. $2 D$ Materials 2016, 3 (4), 041001.

5. Rashid, H.; Rahman, K.; Hossain, M.; Tabet, N.; Alharbi, F.; Amin, N., Prospects of molybdenum disulfide (MoS2) as an alternative absorber layer material in thin film solar cells from numerical modeling. Chalcogenide Letters 2014, 11 (8), $397-403$.

6. Ahmad, H.; Monajemi, H.; Thambiratnam, K.; Ismail, M., Mode-locked near-infrared thulium doped fibre laser using evanescent field effect with Bi2O3 saturable absorber. Laser Physics 2019, 29 (5), 055104.

7. Chong, W.; Yap, Y.; Behameen, S.; Ahmad, H., Study of a high output coupling ratio Q-switched erbium-doped fibre laser using MoS2 saturable absorber. Laser Physics 2017, 27 (2), 025104.

8. Kadir, N.; Ismail, E. I.; Latiff, A. A.; Ahmad, H.; Arof, H.; Harun, S. W., Transition metal dichalcogenides (WS2 and MoS2) saturable absorbers for mode-locked erbium-doped fiber lasers. Chinese Physics Letters 2017, 34 (1), 014202.

9. Reduan, S. A.; Ahmad, H., Molybdenum disulfide (MoS2)-based, tunable passively Q switched thulium-fluoride fiber (TFF) laser. Malaysian Journal of Fundamental and Applied Sciences 2017, 13 (4), 572-575.

10. Ahmad, H.; Tiu, Z. C.; Zarei, A.; Suthaskumar, M.; Salim, M. A. M.; Harun, S. W., Domain-wall dark pulse generation in fiber laser incorporating MoS 2. Applied Physics B 2016, 122 (4), 69. 
11. Novoselov, K. S.; Geim, A. K.; Morozov, S. V.; Jiang, D.; Zhang, Y.; Dubonos, S. V.; Grigorieva, I. V.; Firsov, A. A., Electric field effect in atomically thin carbon films. science 2004, 306 (5696), 666-669.

12. Zeng, Z.; Yin, Z.; Huang, X.; Li, H.; He, Q.; Lu, G.; Boey, F.; Zhang, H., Single-Layer Semiconducting Nanosheets: Highyield preparation and device fabrication. Angewandte Chemie International Edition 2011, 50 (47), 11093-11097.

13. Ambrosi, A.; Sofer, Z.; Pumera, M., Lithium intercalation compound dramatically influences the electrochemical properties of exfoliated MoS2. Small 2015, 11 (5), 605-612.

14. Rashid, H.; Rahman, K. S.; Hossain, M. I.; Nasser, A. A.; Alharbi, F. H.; Akhtaruzzaman, M.; Amin, N., Physical and electrical properties of molybdenum thin films grown by DC magnetron sputtering for photovoltaic application. Results in Physics 2019, 14, 102515.

15. Chelvanathan, P.; Rahman, K. S.; Hossain, M. I.; Rashid, H.; Samsudin, N.; Mustafa, S. N.; Bais, B.; Akhtaruzzaman, M.; Amin, N., Growth of MoOx nanobelts from molybdenum bi-layer thin films for thin film solar cell application. Thin Solid Films 2017, 621, 240-246.

16. Rosman, N. N.; Yunus, R. M.; Minggu, L. J.; Arifin, K.; Kassim, M. B.; Mohamed, M. A. J. J. T., Chemical vapor deposition growth of molybdenum disulfide for photoelectrochemical hydrogen generation. 2020, 26, 68-74.

17. Lin, Y.-C.; Zhang, W.; Huang, J.-K.; Liu, K.-K.; Lee, Y.-H.; Liang, C.-T.; Chu, C.-W.; Li, L.-J., Wafer-scale MoS 2 thin layers prepared by MoO 3 sulfurization. Nanoscale 2012, 4 (20), 6637-6641.

18. Balendhran, S.; Ou, J. Z.; Bhaskaran, M.; Sriram, S.; Ippolito, S.; Vasic, Z.; Kats, E.; Bhargava, S.; Zhuiykov, S.; Kalantar-Zadeh, K., Atomically thin layers of MoS 2 via a two step thermal evaporation-exfoliation method. Nanoscale 2012, 4 (2), 461-466.

19. Ahmad, H.; Rashid, H.; Ismail, M. F.; Thambiratnam, K., Fabrication and Characterization of Tungsten Disulphide/Silicon Heterojunction Photodetector Illuminated Near Infrared. Optik 2019.

20. Lee, B. H.; Park, S. H.; Back, H.; Lee, K., Novel Film-Casting Method for High-Performance Flexible Polymer Electrodes. Advanced Functional Materials 2011, 21 (3), 487-493.

21. Rashid, H.; Sapiee, N. M.; Arsad, N.; Ahmad, H.; Bakar, A. A. A.; Reaz, M. I., Fabrication of a carbon nanotube/tungsten disulfide visible spectrumphotodetector. Applied Optics 2021, 60 (10), 2839-2845.

22. Ahmad, H.; Rashid, H., $405 \mathrm{~nm}$ ultraviolet photodetector based on tungsten disulphide thin film grown by drop casting method. Journal of Modern Optics 2019, 66 (18), 1836-1840.

23. Lee, H. S.; Min, S.-W.; Chang, Y.-G.; Park, M. K.; Nam, T.; Kim, H.; Kim, J. H.; Ryu, S.; Im, S., MoS2 nanosheet phototransistors with thickness-modulated optical energy gap. Nano letters 2012, 12 (7), 3695-3700.

24. Choi, W.; Cho, M. Y.; Konar, A.; Lee, J. H.; Cha, G. B.; Hong, S. C.; Kim, S.; Kim, J.; Jena, D.; Joo, J., High-d etectivity multilayer MoS2 phototransistors with spectral response from ultraviolet to infrared. Advanced materials 2012, 24 (43), $5832-5836$.

25. Park, M. J.; Park, K.; Ko, H., Near-infrared photodetector achieved by chemically-exfoliated multilayered MoS2 flakes. Applied Surface Science 2018, 448, 64-70.

26. Zhou, Y. H.; An, H. N.; Gao, C.; Zheng, Z. Q.; Wang, B., UV-Vis-NIR photodetector based on monolayer MoS2. Materials Letters 2019, 237, 298-302.

27. Berkdemir, A.; Gutiérrez, H. R.; Botello-Méndez, A. R.; Perea-López, N.; Elías, A. L.; Chia, C.-I.; Wang, B.; Crespi, V. H.; López-Urías, F.; Charlier, J.-C., Identification of individual and few layers of WS 2 using Raman Spectroscopy. Scientific reports $2013,3,1755$.

28. Xia, F.; Wang, H.; Xiao, D.; Dubey, M.; Ramasubramaniam, A., Two-dimensional material nanophotonics. Nature Photonics 2014, 8 (12), 899.

29. Ehlen, N.; Hall, J.; Senkovskiy, B. V.; Hell, M.; Li, J.; Herman, A.; Smirnov, D.; Fedorov, A.; Voroshnin, V. Y.; Di Santo, G., Narrow photoluminescence and Raman peaks of epitaxial MoS2 on graphene/Ir (1 1 1). 2D Materials 2018, 6 (1), 011006.

30. Kim, T.; Kim, D.; Choi, C. H.; Joung, D.; Park, J.; Shin, J. C.; Kang, S.-W., Structural defects in a nanomesh of bulk MoS2 using an anodic aluminum oxide template for photoluminescence efficiency enhancement. Scientific Reports 2018, 8 (1), 6648.

31. Sun, P.; Ma, R.; Wang, K.; Zhong, M.; Wei, J.; Wu, D.; Sasaki, T.; Zhu, H., Suppression of the coffee-ring effect by selfassembling graphene oxide and monolayer titania. Nanotechnology 2013, 24 (7), 075601.

32. Mawlong, L. P.; Paul, K. K.; Giri, P. In Simultaneous photoluminescence enhancement in CVD grown single layer MoS2 and TiO2 NRs in the MoS2@TiO2 heterojunction, AIP Conference Proceedings, AIP Publishing: 2019; p 040004.

33. Ahmad, H.; Tamil, T., High responsivity, self-powered carbon-zinc oxide hybrid thin film based photodetector. Applied Nanoscience 2018, 8 (7), 1755-1765.

34. Wang, L.; Jie, J.; Shao, Z.; Zhang, Q.; Zhang, X.; Wang, Y.; Sun, Z.; Lee, S. T., MoS2/Si heterojunction with vertically standing layered structure for ultrafast, high-detectivity, self-driven visible-near infrared photodetectors. Advanced Functional Materials 2015, 25 (19), 2910-2919.

35. Esmaeili-Rad, M. R.; Salahuddin, S., High performance molybdenum disulfide amorphous silicon heterojunction photodetector. Scientific reports 2013, 3, 2345.

36. Li, Y.; Xu, C.-Y.; Wang, J.-Y.; Zhen, L., Photodiode-Like Behavior and Excellent Photoresponse of Vertical Si/Monolayer MoS2 Heterostructures. Scientific Reports 2014, 4 (1), 7186.

37. Liu, X.; Hu, S.; Lin, Z.; Li, X.; Song, L.; Yu, W.; Wang, Q.; He, W., High-Performance MoS2 Photodetectors Prepared Using a Patterned Gallium Nitride Substrate. ACS Applied Materials E Interfaces 2021.

38. Selamneni, V.; Raghavan, H.; Hazra, A.; Sahatiya, P., MoS2/Paper Decorated with Metal Nanoparticles (Au, Pt, and Pd) Based Plasmonic-Enhanced Broadband (Visible-NIR) Flexible Photodetectors. Advanced Materials Interfaces 2021, 8 (6), 2001988. 
